Covered in: Web of Sciences (WOS); EBSCO; ERIH+; Google Scholar; Index Copernicus; Ideas RePeC; Econpapers; Socionet; CEEOL; Ulrich ProQuest; Cabell, Journalseek; Scipio; Philpapers; SHERPA/RoMEO repositories; KVK; WorldCat; CrossRef; CrossCheck

2018, Volume 9, Issue 1, pages: 35-44 | doi: https://doi.org/10.18662/po/04

\section{A Few Jungian Observations on the Psychological Dynamics of the Couple}

\section{Marius Constantin CUCU ${ }^{1}$, Oana Elena LENT, ${ }^{* 2}$}

1 "Ştefan cel Mare" University, Suceava, România, mariuscucu35@yahoo.com

2 "Ștefan cel Mare" University, Suceava, România, oanalenta@yahoo.com

Corresponding author
Abstract: The anima and animus pair constitute, in the Jungian psychoanalytical thinking, one of the most important and representative units for the mobility of the human psyche. Basically, around this ontic couple and the inter-relations of its structures are developing a multitude of creative and exploratory manifestations of the human being. The relationship with the other, during the process of falling in love, is often a central justification for the artistic elaboration or for the development of real nature, but also for the existence of a new life. What role should be given, in this context, to the dimension of the individual unconscious, and in particular, the collective one? How does the Jungian analytics delimit the periods of development, stagnation and even psychological setback of the couple? What benchmark divides the time of the couple and how can the temporal segments of these results be defined? What capacity of influence do the parents exert on the young members of a newly formed couple? What does the harmfulness of this influence consist in and what are its unconscious motivations? Jung's arguments are all the more interesting as the challenges of postmodernism and the contemporary couple always invite to reflect on constitutive grounds and possible ways of understanding or interpretation.

Keywords: Couple, marriage, scope of childhood, destiny compulsion, fenomenality of falling in love, instinct, biological goal, relationality.

How to cite: Cucu, M.C., \& Lenta, O.E. (2018). A Few Jungian Observations on the Psychological Dynamics of the Couple. Postmodern Openings, 9(1), 35-44. https://doi.org/10.18662/po/04 


\section{Introduction}

The psychological dynamics of the interactive nucleus represented by the marriage between a man and a woman represents, from the perspective of the Jungian psychoanalytical thinking, one of the most complex themes of the psychological endeavour. This sphere of the couple reunited under the authority of marriage involves the connection between multiple subjective and objective data. For the psychoanalytic exploration, the objective data, the information that highlight legal and social landmarks, occupy a second place. What matters here is, first and foremost, the psychic factor, represented by the evidences of the psychic mobility related to marriage. If, therefore, one can say that the marriage is a psychological relationship, then it must involve a report of conscience, more precisely, a ratio between two consciousnesses. One cannot speak about the connection of two unconsciousnesses, but about the connection of two units of consciousness that both have an unconscious sphere, about the symbiosis of two cores that balance and compensate one another (Jung, 2007), finding themselves the one within the other, the conceptual duality anima-animus being relevant for this active con-substantiality (Neumann, 1989). Therefore, the relationship within marriage implies the intersection of two consciousnesses that are dragged, each of them, on two universes of unconscious psychic nature. As regards the presence and the dynamics of corporeality, as significant factor within a marriage relationship, it can only represent, in the Jungian psychoanalytic opinion, a tool of expression of psychic drives occurring from the unconscious and assumed by the architecture of the consciousness. The body language is, in essence, the language of the psyche transposed to the level of the lively materiality.

\section{Psychological Dynamics of the Couple}

From the perspective of the Jungian psychoanalytic thinking, in order to understand the mental frames activated at the individual level within the involvement in a marriage, we must look first at the genesis and personal consciousness from the stages of childhood. Thus, for a child, the sphere of consciousness comes from the depths of his psychic being, like certain islands, like disparate fragments scattered on the ocean of the active unconsciousness. Subsequently, with every passing year, these islands get closer and bigger, generating the emergence of what Jung calls the continents of the individual consciousness. Only in so far as they reinforce an ample and firm ground of the consciousness, do we get a statutory 
identity that can open the interaction with another consciousness, in its turn, evolved and emancipated through the detachment of the structural fragmentary phases. During this period, the consciousness develops, like a revolving door, over the individual unconsciousness that interacts constantly with the collective unconsciousness. The fact that two consciousnesses reach the pinnacle of their systemic consolidation does not prevent, but on the contrary, potentiates, according to Jung, the influence, from the depths of the soul, of the unconscious drives and psychic energies. They often decide the evolution of the relationship that culminates by marriage, and determine major changes inside it. Of course, one cannot talk about a relationship between two unconsciousnesses, but it may be issued, from Jung's perspective, the idea that behind every marriage or relationship between a man and a woman, there is the decisive influence imposed by the dynamics of the unconsciousness of the two individualities and the collective unconsciousness. The Jungian psychoanalytical thinking intervenes here with the idea that, at the unconscious level, one cannot talk about a relationship between two people because, essentially, at this level, since the primary spiritual condition dominates from the very beginning, the spirits are more close to one another. There is, in the unconscious dynamics, the tendency of an identification between the spiritual entities, so that often when it is said, at the conscious level, that two people find out they are compatible, they actually let themselves be guided by the unconscious sources of a closeness and of psychic complementarities that already exist. When two consciousnesses are compatible and get on well with each other, they manifest information and meanings of unconsciousnesses that govern them on the sly, behind the curtain of conscious life. According to Jung, although the moment of marriage indicates a higher threshold of adulthood and consciousness, however, the universe of the unconsciousness continues to dominate in a mysterious way the entire perimeter of conscious events. The withdrawal of the unconscious or the refocusing of psychic attention from the unconscious drives to consciousness does not mean or equate with the interruption of the connections between unconscious and conscious. On the contrary, the entire mainland of consciousness thus reunited and strengthened through the symbiosis of those dissipated formations of the consciousness arising from childhood, is floating on the endless ocean of the individual unconsciousness which is extended in the boundlessness of the collective unconsciousness. The young man who considers himself apt for marriage and who feels his consciousness as a consolidated structure, does not know himself essentially and, even less does he know the person he chooses to be his partner. In fact, what he does not know is the dimension 
of the unconsciousness and the pulsatile and dominant force of this latter. The reasons for choosing a particular person to marry to, remains an aspect as inexplicable as the fact of falling in love that often occurs as a run-up of marriage. Jung will assume that the unconsciousness chooses for the consciousness, essentially the major decisions in the human destiny come from the individual and collective unconsciousness. Therefore, the decision to opt for a particular person, and how one can fall in love with them cannot come from the area of the consciousness mobility. These phenomena have their origin and primary energy resource in the dynamics of the unconsciousness. Jung will name this aspect the destiny compulsion, considering that the attraction and the closeness of two people manifests over or even despite the external space and time conditions, thanks to this unconscious magnetism that reunites those two entities in defiance of any obstacle or barrage occurred in the interactions of the consciousness. The decision of the unconsciousness is appropriate here and finds the most innovative formulas for fulfilment, often in situations that are totally divergent from the events generated by the unconscious drives. Thus, the dramatic or positive events are often unpredictable and cannot be predicted by the conventional consciousness, but they are predicted or anticipated through the call to the informative mechanisms of the unconsciousness, mechanisms that are focused on the symbolic and archetypal expression, on the oniric or visionary experience, that occupies here a decisive role (Jung, 2006).

The unconsciousness, both the individual and collective one, remains, considers Jung, in its greatest part, a conundrum for the most elaborate psychoanalytic explorations. In this context, it can be said that the mechanism of the destiny compulsion remains, overall, non-definable. However, in addition to an extensive dynamics and operationality that we are not able to understand and to quantify in the parameters of the psychoanalytical research, there are also definable components, which play an important role in the unconscious mobility of the couple. One of these components is, according to Jung, (Jung, 2006) the influence of parents on the childhood, adolescence, and sometimes, on the entire life of the individual. The Jungian psychoanalysis will refer here to two specific trends. One of them is related to the attachment to a certain parent. In general, the boy stands constantly under the sphere of influence and protection of the mother and the girl under the scope of the sovereignty of the father. Therefore, this will cause major influences on the choice for the future husband or wife. In such cases, the husband must be at least as competitive as the father and the wife must prove a substitute of the maternal presence. Thus, the attachment and unconscious drives are involved, obviously, in making the decision regarding the option for a certain type of 
partner on the trajectory of life. A second component that can intervene in the process of influence of the consciousness by unconsciousness in the choice of the partner of marriage is what the psychoanalysis calls the process of compensation. If an individual has lived a childhood and adolescence under the extreme authority of a parent who was a religious or moral fanatic, then he is attracted by an excessively rebellious behaviour, with the revolt turning from an impulsive and oscillatory state, into a constant way of living. Obviously, such a personality will not accept an individuality that is similar to the parent from whose authority he has always wanted to escape. On the contrary, if the adolescence and the childhood was lying under the spectrum of a rebel, violent, traumatic parent, it is possible that the person who left from such a toxic psychic influence to be willing to meet a person with a behaviour opposite to the one of the abusing parent. Sometimes, however, the youngster can follow the model of the parent, in fact, he incorporates in another ontic scenario and a desire to marry a possible victim, as he was himself in the past, can prevail. We are dealing here with the inability of the psyche to get rid of the psychic trauma of the past, a trauma which becomes an unconsciously negative pulsatile drive. Here the mechanism of compensation or roll-over of psychic data through the attachment for a person with a temperament opposed to the parent is blocked by the sedimentation of the parental influence on the level of the unconscious telluric.

Jung will delineate two instances representing the issue of the unconscious area of a relationship, often completed by marriage, between a woman and a man. There is, therefore, the scenario of the massive parental influence that, frequently, can only manifest itself through the unleash of unconscious blockage specific to one of both parents. Here, the frustrations, the inferiority complexes, the sexual traumas, the emotional breaches and dissimulated failures, all these negative sediments accumulated by a parent's unconsciousness may blow out with the novelty of the context in which his successor manifests the vicinity and the intertwining of his own destiny with that of a person chosen intuitively to be a real presence in a long emotional partnership. In such a scenario, the parent will intervene under the motivation of morality and life experience, being waged in this endeavour, by that stream of negative psychic storage and by the need of getting rid of their burden, cumulated over time. The parent pretends to be here a specialist in feelings and the one who has to make the final decision, so here manifests an act of compensation of the past in which, often, were confirmed the inabilities and the deficiencies inherent to his existence. $\mathrm{He}$ relives the hope of acquiring and exercising an authority which, in essence, he has never had. This situation proves really traumatic for a young person 
wishing to engage in a solid relationship, no step carried out in this direction being possible without acceptation and especially toxic distortion, in terms of psychic area, generated by the energetic and vain influence and intervention of the parent concerned. The overtaking of this influence often equates with a decisive conflict, developed, in particular, between the son and the father or the mother and the daughter. The natural tendency of manifestation of the development and evolution from the harmful and overpowering influence of the parent clashes, therefore, with the firmness of the latter, who attempts to obtain a late, maybe final recognition of his importance and capabilities of leader of the family. The child's options are based on two opposite directions of approach. Thus, either he acts radically, facing the vain wandering of the parent and develops his own road of destiny freed from the spectre of the evil past, or, conversely, he assumes the psychological chaining in relation to gaps and blockages of the parents' unconsciousness and, therefore, takes part in his own involution and anchorage in an emotional circularity that is close to depression and thorough resignation. Such a psychological breakdown is often doubled, as Freud highlights, by a complete anchorage in the state of total attachment in relation to a parent, on the background of the interpretation of the other parent's image as a rival (Freud, 2010a, p. 287). Thus, the major investment in the maternal presence will be opposed to the recognition of the authority of the father, the mother's depiction being assumed as a possession that cannot be shared (Freud, 2010b). This state will also be exported in the possible relationship of the couple, a relationship that will stand under the sign of the arrangement and of the parental decision, which excludes the presence of freedom of choice and reduces significantly the chances of a massive emotional investment of the two partners of the couple. In this sphere also finds its place what has been called throughout history marriage out of interest, with the interest being often dictated by the parents. The second scenario mentioned by Jung as a representative picture of the couple relationship, in relation to its unconscious mental grounds, is that type of relationship between a woman and a man that is generated and guaranteed by the phenomenon already evoked that Jung names using the term of destiny compulsion. What holds the decisive influence and control here are the unconscious influences which have arisen from the psychological depths of the two protagonists of the couple relationship. Therefore, the external resonances, the modulations coming from the parents' opinions or those nearby, as well as the binding traditions, religion or active fashion cannot interfere with this stream of unconscious imperatives erupting from the two partners' unconsciousness. Jung insists here on the idea that the true state of 
falling in love assumes a return into the abyss of the absence of consciousness, in a primordial area, where the individual unconsciousness is familiarized with the symbiosis and perfect harmony. In essence, this area is the one of the collective unconsciousness, where is induced the absolute condition of maternity, of primary care. Jung considers that the two experience, thus, otherwise than following the religious path, the meeting with the authentic experience of the divine, the genuine love for each other with profound similarities with the mystic exacerbation. And here we are witnessing, considers Jung, the exceeding of the simple drives of corporality and a leap into the spiritual area, doubled by the activation of an intense sense of sacrifice for each other. Experiencing the feeling of love towards each other entails, in this context, a reconfiguration of the entire perception of the world, the tale of the collective unconsciousness descends over the circumscriptions of the consciousness linked to space and time. The lovers are floating, in their overflowing affection, over the immanent rationality, they defy the logic dimension and their affection game seems to be the sole factor of ontic and gnoseologic guidance. Thus, their existence and knowledge revolve around the love story in which they are completely invested. According to Jung, the lovers relive the experience close to the area of the collective unconscious felt by children, and the two lovers' behaviour is not accidentally described often as childish. The individual will is defeated and subordinated to the unconscious flow emerging from the collective unconscious and bears the two psychic entities to the state of cancellation of their own individual condition. This apotheotical cancellation will be identified by Jung in the conversion state in which the man becomes a father and the woman a mother. The axiomatic of the human evolution is imposed here through the unconscious drives and the force of progression of the human species uses the human being's need to receive and give love, as well as his intolerance in relation to the deep depression of loneliness. The Jungian interpretation is similar, from this perspective, to the vision of Schopenhauer, (Schopenhauer, 1995) who claims the idea according to which the universal Will and its propulsion factor mingles with the relationship between a woman and a man, in order for them to be able to ensure the continuity of human life, the phenomenon of falling in love being only a tool through which the Will and the life fulfil the imperatives of survival at the biological level (Schopenhauer, 1995). Of course, in the case of the first scenario evoked by Jung, we can talk about a transformation of the man into a father and of the woman into a mother, as well as about children. But, in such case, the process is altered, modified, and malformed from a psychic viewpoint, through the interference and domination of the 
parents' psychic drives and syncopes. The trauma of the arrival of a child in the absence of genuine love, only on the basis of forming a family, imposed by parents and formatted according to their paralyzing psychic standards, constitutes a denial of the principle of the human couple and not its fulfilment.

There is, therefore, according to Jung, a procedure which evolves from a psychological point of view of the couple who changes its rhythm and coordinates over time. Referring in particular to that couple that was established on the basis of a genuine, mutual affection, the Jungian psychoanalytic notes that one can speak of a temporal capital landmark that delimitates or, more accurately, divides the couple's life in two major ontic stages or eras. Thus, this landmark, identified as the general average norm of human life, so somewhere around the age of 40 years, is the one that marks the transition from one paradigm and a certain kind of life perception to another stage of relating to the existence. The first part of the couple relationship and of the connection with the presence of the child as a result of the love developed within the couple, is characterized by major investments, by axiomatic projections over certain segments of life, of construction and development on the background of a constant list of welldefined ideals and purposes. Here we find the feelings of hope, selfconfidence, often self-sufficiency, reckless tendency of heading for new life horizons. At the same time, through the emergence of the child, also appears the area in which the parent can find himself or can recalibrate the entire configuration of his own being as a pedagogical leader and source of education for the being who is only at the beginning of his life (Apostu, 2017a, 2017b). The parent assumes here the role of guide, of unique opener towards the symbolic meaning but also the dangers of life. He requires his child to obey, because of love, but also out of a need to confirm their own value and personality. With the entry in the second psychic dimension of life through the growing up of their own child, who reaches the age of 40 , the parents is confronted with the reality of the inversion of values which he believed stable. Thus, it appears that the one he used to consider a child forever became, in turn, a grown-up, often caught in the gears of a couple, and that the directions of life of this latter differ substantially from what the parent had suggested beforehand. His axiomatic, as a parent, collapses, making room for another hierarchy of values(Lența, Tărnăuceanu, \& Cormos,, 2013; Terec Vlad, 2017). The creation overcomes its creator, and its ascension becomes horizontal positioning, settlement on the flat line of life. As Jung observes, passion becomes duty, love turns into respect, with the parent feeling the past as being increasingly charged compared to the 
future. A parent who is strongly attached to his offspring will exert the same pressure on the child as the one he used to feel himself in his childhood and the separation from his own offspring will not be devoid of incidents and negations, of alleged blames, materialized by the bringing into question of the lack of respect for parents. Any such parent, considered essentially conservative, will interpret the separation of his child from his area of influence as a riot and an act of insult. It is the dissimulated form through which the voice of conservatism shall require its rights. However, the process of separation cannot be dimmed and the two parents, who, in the context of their conservatism, apparently belong to those couples in which the genuine love is absent, must resign in the end (Jung, 2006, pp. 211-213). For a situation in which the couple was founded on genuine love, the separation from the child is more easily tolerated, as it is perceived as a replay of the state of emotional purity, that used to influence the respective parents in their youth.

\section{Conclusions}

These aspects underlined by Jung in relation to the typology of the couple, but also to the periods of its development in relation to the child, come to indicate the psychological dynamics of the couple, the fact that this fundamental unit of human interaction depends on the flows of the psychic experience, experience that has, overall, an unconscious nature. Jung places, therefore, at the base of the relationship between a woman and a man, the telluric area of the unconsciousness, as he does in relation to the mythical and religious dimension, to the cultural or oniric one. Beyond the notion of couple there are unconscious drives that influence the rules of social convention, the tradition and the current imperatives of the ephemeral mundane. Jungian researches on the dynamics of psychic inter-connections in the human sphere have opened new perspectives, unsuspected and hardly tolerated by the mentality of the 19th century vision of the human soul. These researches and analytics, located between the paradigms of theory and psychological practice, gradually gave a new impetus to the whole field of approaches to the human psyche. From these resurrection mobilities, the propedeutics of the new post-modern approaches to the phenomenon of being in the couple, as well as to the whole area of complexity related to the inter-human relationship, were launched. From these positions, postmodernism tried to distance itself from the traditional axiomatic that imposed certain ethical and religious standards and rules of ethics. But this conceptual departure must not be equated with the renunciation of moral 
principles that have not been denied, but only settled and assumed in a new theoretical-empirical configuration.

\section{References:}

Apostu, I. (2017a). Female management, between motherhood and career. Ecoforum Journal 6(1).

Apostu, I. (2017b). Postmodernity and the Solidarity Dilemma - a Challenge for the Contemporary Couple. Postmodern Openings 7(2), 9-12.

Freud, S. (2010b). Declinul complexului Oedip. In Opere esentiale (Vol. 5). Bucuresti: Trei Publishing House.

Jung, C. G. (2006). Dezvoltarea personalitatii. Bucharest: Trei Publishing House.

Jung, C. G. (2007). Doua scrieri despre psihologia analitica. Bucharest: Trei Publishing House.

Lența, O., Tărnăuceanu, F., \& Cormoș, C. (2013). Violence and Incoherence Parenting Patterns - Potential Risk Factor in Distorting the Child's View on Reality. Elsevier: Procedia - Social and Behavioral Sciences, 92, 467 - 473 doi:https://doi.org/10.1016/j.sbspro.2013.08.703

Neumann, E. (1989). The Origins and History of Consciousness.

Schopenhauer, A. (1995). (Vol. 1). Iasi: Moldova Publishing House

Terec Vlad, L. (2017). The Family Where to? From the „Solid” Perspective to „Liquid” Perspective. Postmodern Openings, , 8 (1). 